\title{
The Learning Journal Bridge: From Classroom Concepts to Leadership Practices
}

\author{
Rosemary Maellaro, Ph.D. \\ Assistant Professor of Management \\ College of Business, University of Dallas \\ Irving, TX 76062 \\ rmaellaro@udallas.edu \\ 972-789-1922
}

\begin{abstract}
The value of reflective writing assignments as learning tools for business students has been well-established. While the management education literature includes numerous examples of such assignments that are based on Kolb's (1984) experiential learning model, many of them engage only the first two phases of the model. When students do not move through the complete model, they are less likely to take what they learn from the classroom to the workplace. This article describes a graduate learning journal assignment that incorporates all phases of Kolb's model. The assignment's success in creating a bridge between simply learning about leadership and actually putting leadership knowledge into practice is grounded in three learning theories.
\end{abstract}

\section{Introduction}

Reflective writing assignments in business education take many different forms with varying degrees of depth and structure, but their common purpose is to enhance learning. By requiring students to question their assumptions, surface tacit knowing, and reflect on how to integrate course content with personal experience, learning journals actively involve students in their own learning. This highly participative process can expand a student's capacity to acquire leadership knowledge (Castelli, 2011; Daudelin \& Hall, 1997; Moon, 2006; Moore, Boyd, \& Dooley, 2010; Roberts, 2008; Varner \& Peck, 2003).

Learning journal assignments also are intended to guide students in using the insights gained through reflection as the basis for assessing their current skills and expanding the focus of their practice to be more effective leaders (Jarvis, 2001; Moon, 2006; Moore, et al., 2010). In light of this, Kolb's (1984) experiential 
learning model provides a logical framework for learning journal assignments. It is a learning cycle that combines the way students acquire new knowledge and the process by which they make it meaningful. It entails the following four phases:

- Concrete Experience - being involved with what is occurring in the here and now.

- Reflective Observation - understanding the meaning of experience through careful observation and impartial description of different perspectives.

- Abstract Conceptualization - using logic, ideas, and concepts to build general theories about experiences and new perspectives.

- Active Experimentation - making changes by applying new general theories to personal situations.

This learning sequence is continually repeated. As one cycle ends, the last phase (i.e., active experimentation) then becomes the first phase (i.e., concrete experience) for the next cycle. Despite the comprehensive nature of the model, many learning journal assignments focus only on the first two phases while neglecting the last two (Smith \& Roebuck, 2010). Daudelin and Hall (1997) suggest that to capitalize on the insights gained from reflective assignments, students should be required to determine how they will use new ideas at work and describe the potential implications of applying the new ideas. In other words, to maximize learning, students should complete the entire learning cycle.

The learning journal assignment I use in my graduate leadership courses takes students through all four phases of Kolb's (1984) model. This aspect of the assignment is significant because it treats learning "as a holistic adaptive process" and "it provides conceptual bridges across life situations such as school and work" (p. 33).

\section{The Learning Journal Assignment}

My assignment is structured, consisting of three specific parts: (a) insight gained from class materials and/or activities, (b) application of insights on the job, and (c) implications for effectively leading organizations. The purpose of the assignment is to focus students' attention on what they learn about leadership concepts and how they plan to use their learning. The assignment also asks students to recognize the positive impact their improved leadership practices can have on the overall effectiveness of their organizations.

Students submit six journals throughout a 12-week term. They write in the first person from the perspective of a leader rather than a subordinate employee. Students who do not hold leadership positions write in the future tense to describe 
what they will do when they become leaders. Students with limited work experience are not at a disadvantage in this regard. Learning journal quality is differentiated more by students' reflection and conceptualization skills than by work experience.

In the following sections I describe each part of my learning journal assignment in greater detail. I also address questions of grading, feedback, and the assignment's theoretical underpinnings.

\section{Part One: Insight}

In this part of the journal students share an insight they gained in class, which may come from readings, lectures, discussions, assessments, team activities, or experiential exercises that comprise their concrete experiences (Kolb's, 1984, phase one). An insight is more than a simple recapping of basic elements, terminology, categories, and techniques associated with a topic. I expect students to move beyond merely reciting factual, conceptual, or procedural knowledge in order to demonstrate a more complex level of understanding (Krathwohl, 2002; Reynolds, 1998). Articulating insights requires students to determine the meaning of instructional messages through interpretation or inference (Krathwohl, 2002). I ask students to consider the concrete experience from various perspectives (English, 2001). In so doing, students are engaging in reflective observation (Kolb's, 1984, phase two).

The following example is an excerpt from a student's learning journal insight section:

- The new learning I took away from our class activities this week came from the Emotional Intelligence Leadership Competency exercise. Although I appear to have a good platform of emotional intelligence to develop my leadership capability, I have low self-management and mid to low self-awareness. When reviewing the specific questions associated with these dimensions, I realized that, although I tend to know when I am getting angry, I have difficulty knowing when I am becoming defensive.

\section{Part Two: Application}

In this part of the assignment students explain how they will use the insight described in part one. Students must move to abstract conceptualization (Kolb's, 1984, phase three) to think about how they will use their new knowledge to improve their leadership practices. I want students to be very specific here. I instruct them to use action verbs rather than saying they will be more aware of 
something or will try to do something better. This requires students to progress to active experimentation (Kolb's, 1984, phase four) as they envision themselves applying new behaviors.

The following is an excerpt from part two of a learning journal that describes the student's plan to apply their learning:

- After intense interactions with my peers, I will take a step back and look at the big picture, especially in the complex situations. I will make a chart where I will list the individual I was speaking with, the situation we were involved in, the outcome, and the emotions felt both during the situation and after the outcome. I will have my chart available during future telephone interactions as a reminder to monitor myself. I will also review the chart at the end of each week to look for any situational trends where I feel negative emotions and become defensive so I can make further plans to improve in this area.

\section{Part Three: Implications}

This part of the assignment is one that is typically not seen in all learning journal assignments. Here students identify how the application of what they learned will contribute to the overall success of their organizations. A student's ability to look outside oneself in order to understand how to connect to the whole is essential to the application of learning (Roberts, 2008). By doing this, students can recognize the potential benefit of their new behavior which will make them more likely to actually carry out their application plans (Merriam, 2001).

Following is an example of a student's learning journal implication section:

- By understanding and verbalizing my strengths and weaknesses, my team will see I am open to learning and actively seeking self-improvement. This could help cultivate a more trusting relationship between us. Our text states quality employees are one of the best predictors of a firm's financial potential. Being more aware of my emotions can help generate better relationships that will lead to a more positive work atmosphere. This would ultimately result in more productive employees for [the company], thus increasing our bottom line.

\section{Grading and Feedback}

Much debate surrounds the question of whether learning journals should be graded (Varner \& Peck, 2003). Some critics of grading have voiced concern that 
it will stifle the students' candor and hinder the depth of learning. Others are concerned that ethical issues may arise if journals include inappropriate levels of self-disclosure (English, 2001).

Student candor has not been an issue with this assignment because of the structured format and specific content I require. While I do ask students to consider their personal thoughts and feelings, I instruct them to focus on business rather than personal applications of the material. I grade journals using a rubric similar to the one in Table 1, which I also ask students to use to inform their writing. I focus more on content than style; however, I do expect journals to be written professionally and to flow logically.

Table 1

Sample Learning Journal Grading Rubric

\begin{tabular}{|l|c|}
\hline Criteria & Deductions \\
\hline Simple reiteration of concepts or activities & 15 \\
\hline Incorrect interpretation of concept/theory/model & $5-20$ \\
\hline Lack of depth of insight & $5-15$ \\
\hline Insight not clearly articulated & $5-15$ \\
\hline Application not related to insight & $5-20$ \\
\hline Improper application of concept/theory/model & $5-20$ \\
\hline Lack of specificity or incomplete application plans & $5-20$ \\
\hline Implication not related to application & $3-10$ \\
\hline Missing or incomplete implication & $5-15$ \\
\hline Unclear link between application \& implication & $3-10$ \\
\hline Not written from management perspective & $3-20$ \\
\hline Writing in second or third person & $5-10$ \\
\hline Grammar, spelling & $2-10$ \\
\hline
\end{tabular}

I provide descriptive feedback in addition to numerical grades. Although this can be time-consuming, the feedback students receive from me is an important element of the learning process. Feedback that is non-judgmental and positive is more readily accepted by students (Brookheart, 2008); therefore, I include positive comments where sections of the journal are particularly discerning or applicable. I also make it a point to use non-evaluative words so students will be motivated to improve rather than react defensively to my feedback. Unless students have not grasped the essence of a concept or they plan to apply the concept incorrectly I do not indicate that anything is necessarily wrong. Instead, I pose questions intended to make students rethink aspects of their journals that may be incomplete or off target. 


\section{Discussion}

The effectiveness of my learning journal assignment is supported by three key learning theories - Bloom's taxonomy, learning transfer, and principles of andragogy (adult learning).

Bloom's taxonomy is a hierarchy of learning levels: (a) remembering, (b) understanding, (c) applying, (d) analyzing, (e) evaluating, and (f) creating (cited in Krathwohl, 2002). Learning journal assignments that do not include all phases of Kolb's (1984) model typically do not move students beyond Bloom's lower learning levels. My assignment incorporates all four phases of Kolb's model and thus brings students to Bloom's higher levels of learning as follows:

- The insight part of the journal assignment requires students to participate in class activities (i.e., concrete experience) and then think back upon those activities (i.e., reflective observation) to infer meaning from them. At this point students must remember and understand, which indicates they are learning at Bloom's (cited in Krathwohl, 2002) first and second levels.

- As they plan how to use their new knowledge (i.e., abstract conceptualization and active experimentation) in part two of the assignment, they are learning at Bloom's third and fourth levels. That is, in the process of articulating how they will implement new behaviors in given situations, students analyze their insights and think about how to apply their knowledge (cited in Krathwohl, 2002).

- For part three of the learning journal, students consider how the application of their new learning will contribute to organizational success. In doing so, students evaluate the potential effectiveness of their newly learned behaviors, which puts them at Bloom's (cited in Krathwohl, 2002) fifth learning level.

- Active experimentation becomes concrete experience as students begin Kolb's (1984) four phases anew. By revising their behaviors for the next pass through the model, they must create new application plans. They have now arrived at Bloom's highest learning level (Krathwohl, 2002).

Table 2 shows how my assignment integrates Kolb's (1984) model and Bloom's (cited in Krathwohl, 2002) learning levels. 
Table 2

Assignment/Theory Integration

\begin{tabular}{|c|c|c|}
\hline $\begin{array}{l}\text { Kolb's Experiential } \\
\text { Learning Model Phase }\end{array}$ & $\begin{array}{c}\text { Learning Journal } \\
\text { Assignment }\end{array}$ & $\begin{array}{c}\text { Bloom's Taxonomy } \\
\text { Learning Level }\end{array}$ \\
\hline Concrete Experience & Part 1: Insight & $1-$ Remembering \\
\hline Reflective Observation & Part 1: Insight & 2 - Understanding \\
\hline $\begin{array}{r}\text { Abstract Conceptualization } \\
\text { Active Experimentation }\end{array}$ & Part 2: Application & $\begin{array}{l}3-\text { Analyzing } \\
4-\text { Applying }\end{array}$ \\
\hline & Part 3: Implication & $5-$ Evaluating \\
\hline \multicolumn{2}{|c|}{$\begin{array}{l}\text { Active Experimentation = Concrete Experience for the } \\
\text { next cycle through the model. It is evaluated to create } \\
\text { new behavior plans }\end{array}$} & 6 - Creating \\
\hline
\end{tabular}

Learning transfer theory addresses the use of learned knowledge or skill back on the job (Burke \& Hutchins, 2007). It offers further insight as to why my journal assignment facilitates the transfer of student learning from concept to practice. By anticipating and articulating exactly how they will apply their learning for part two, students are creating retrieval cues. These cues allow them to pull their learning from the classroom into working memory at the same time they encounter similar situations in the workplace (Omrod, 2004):

The presence or absence of retrieval cues in the transfer situation determines what relevant knowledge, if any, is retrieved to working memory. A new event is more likely to call to mind previously learned information...if the learner anticipated the situation when storing the new information, so that the situation and information relevant to it were stored in a connected fashion. (p. 366)

The andragogical principles of self-directed learning and problem-centered learning further support the argument for guiding students through Kolb's (1984) entire learning cycle. Adults learn best when they take responsibility for their own learning and when they can determine what is important to them. Additionally, they are most interested in acquiring knowledge they can use immediately (Knowles, 1990; Merriam, 2001; Moore et al., 2010).

The learning that occurs with part one of the assignments is self-directed because it allows students to choose an insight from the class activity that resonated most with them. Learning is enhanced by allowing students to write about classroom concept(s) that are important to them at the time (Knowles, 1990; Merriam, 2001). For part two of the journal, students must reflect upon and specifically articulate how their learning will be used; in other words, they have to visualize taking those actions (Moore et al., 2010). The self-directed nature of allowing 
students to select a concept that is most relevant to them (i.e., one that will help them solve an immediate problem) makes this visualization process more realistic. This subsequently increases students' self-confidence and sense of responsibility, which can encourage them to actually take the actions they plan (Brown, McCracken \& O'Kane, 2011) and, thus move from concrete experience to active experimentation.

\section{Conclusion}

It is incumbent upon management educators to help students integrate their knowledge of leadership concepts with practical ways of applying that knowledge (Cunliffe, 2004; Hiemstra, 2001). The learning journal assignment I have described here accomplishes that objective. It moves students through all phases of Kolb's (1984) experiential learning cycle, which also helps them progress to the upper levels of Bloom's (cited in Krathwohl, 2002) learning taxonomy. It is here that students can use what they learned to apply, analyze, evaluate, and create effective leadership practices. They are relying on the transfer cues they create in class to move pertinent and practical knowledge to the workplace. The combination of these factors intentionally matches learning from the classroom as closely as possible to the organizational contexts in which students will be required to apply their learning (Armstrong \& Mahmud, 2008). In essence, this is the bridge between school and work that Kolb (1984) envisioned. Anecdotal evidence from my students indicates that many of them have effectively implemented their learning journal application plans to yield successful outcomes. As such, the learning journal assignment served as the blueprint students needed to construct the bridge from classroom concepts to leadership practices. 


\section{References}

Armstrong, S. J., \& Mahmud, A. (2008). Experiential learning and the acquisition of managerial tacit knowledge. Academy of Management Learning and Education, 7(2), 189-208.

Brookheart, S. M. (2008). How to give effective feedback to your students. Alexandria, VA: Association for Supervision and Curriculum Development.

Brown, T., McCracken, M., \& O'Kane, P. (2011). 'Don't forget to write': How reflective learning journals can help to facilitate, assess and evaluate training transfer. Human Resource Development International, 14(4), 465481.

Burke, L. A., \& Hutchins, H. M. (2007). Training transfer: An integrated literature review. Human Resource Development Review, 6(3), 263-296.

Castelli, P. A. (2011). An integrated model for practicing reflective learning. Academy of Educational Leadership Journal, supplement, 15 (Special Issue), 15-30.

Cunliffe, A. L. (2004). On becoming a critically reflexive practitioner. Journal of Management Education, 28(4), 407-426.

Daudelin, M. W., \& Hall, D. T. (1997). Using reflection to leverage learnings. Training \& Development, 51(12), 13-14.

English, L. (2001). Ethical concerns relating to journal writing. New Directions for Adult and Continuing Education, 90, 27-35.

Hiemstra, R. (2001). Uses and benefits of journal writing. New Directions for Adult and Continuing Education, 90, 19-26.

Jarvis, P. (2001). Journal writing in higher education. New Directions for Adult and Continuing Education, 90, 79-86.

Knowles, M. (1990). The adult learner: A neglected species. (4 ${ }^{\text {th }}$ ed.) Houston: Gulf Publishing.

Kolb, D. A. (1984). Experiential learning: Experience as the source of learning and development. Englewood Cliffs, NJ: Pearson Education. 
Krathwohl, D. R. (2002). A revision of Bloom's taxonomy: An overview. Theory into Practice, 41(4), 212-218.

Merriam, S. B. (2001). Andragogy and self-directed learning: Pillars of adult learning theory. New Directions for Adult and Continuing Education, 89, 3-13.

Moon, J. A. (2006). Learning journals: A handbook for reflective practice and professional development. New York: Routledge.

Moore, C., Boyd, B. L., \& Dooley, K. E. (2010). The effects of experiential learning with an emphasis on reflective writing on deep-level processing of leadership students. Journal of Leadership Education, 9(1), 36-52.

Omrod, J. E. (2004). Human Learning (4 ${ }^{\text {th }}$ ed.). Upper Saddle River, NJ: Pearson.

Reynolds, M. (1998). Reflection and critical reflection in management learning. Management Learning, 29(2), 183-200.

Roberts, C. (2008). Developing future leaders: The role of reflection in the classroom. Journal of Leadership Education, 7(1), 116-129.

Smith, D. N., \& Roebuck, D. B. (2010). Interviews: Linking leadership theory to practice. Journal of Leadership Education, 9(2), 135-143.

Varner, D., \& Peck, S. R. (2003). Learning from learning journals: The benefits and challenges of using learning journal assignments. Journal of Management Education, 27(1), 52-68. 


\section{Author Biography}

Rosemary Maellaro is an assistant professor of management at the University of Dallas College of Business where she teaches graduate courses in leadership and organization development. After holding senior-level corporate human resource management positions for several years, she received her doctorate in Human and Organizational Development from Fielding Graduate University in 2008. Her research interests lie in the areas of management education and interpersonal effectiveness. Additionally, she maintains a consulting practice that specializes in leadership development and team building. 